\title{
Data Privacy Concerns Throughout the Customer Journey and Different Service Industries
}

\author{
Marko Mäki and Ari Alamäki \\ Haaga-Helia University of Applied Sciences, Finland \\ \{marko.maki, ari.alamaki\}@haaga-helia.fi
}

\begin{abstract}
Data privacy concerns play a significant role during collaboration with customers in digital networks. An important element in collaboration between business partners is the utilization of customer data in common offering development, marketing, and service operations. The aim of this paper was to focus on data privacy in the context of the customer journey and in different service industries. Based on empirical survey data $(n=306)$, our findings highlighted the importance of recognizing phases in the customer journey and have drawn attention to information sensitivity in different service industries. Findings showed that customers' willingness to share data with different industries varied. Moreover, consumers' attitudes towards the use of their personal data varied at different phases of the customer journey. Our findings have emphasized the importance of information sensitivity in different phases of the customer journey, especially when designing a means for effective data utilization in collaborative networks.
\end{abstract}

Keywords: data, privacy concerns, customer journey, service industries

\section{Introduction}

Creating a superior customer experience has become a dominant aim and stream of value chains and ecosystems. One important element in developing new digital services is the utilization of customer data in personalization, online service performance monitoring, and sales and marketing operations improvement [1]. While companies have created multichannel designs for customers and have become more data driven in their daily activities, customers, as the most important actors of business ecosystems, have become increasingly concerned about their privacy. Privacy concerns are prevalent, especially in online environments [2,3] where customers and service providers interact in collaborative networks.

Many companies have highlighted the importance of customer experience [4]. Customer experience has become an important part of marketing and service 
development, and it is the basis of the emerging experience economy [see 4]. Successful attempts to build connection with customers and to ensure customer satisfaction and superior customer experience require the use of customer data. There are growing concerns among consumers about revealing personal information, and many are dissatisfied with the way in which some organizations collect and use their information. This may pose a major problem, hampering growth in some areas, such as e-commerce [5]. In general, digital servicescapes and markets pose unique information privacy threats due to two-way communications possibilities [see 5]. Moreover, new General Data Protection Regulation (GDPR) regulations pinpointed data privacy issues when the legislation was enforced within the EU in spring 2018. New regulations have underlined the importance of customer experience in a service context The GDPR regulations has two major aspects related to use of data, the need for permission for the customer data utilization [6] and the more general need for companies to become more customer driven when utilizing data [see 7]. There is an identified research gap concerning to customer preference and choice related to organizational use of their information [3].

The aim of this paper was to focus on data privacy in the context of the customer journey and in different service industries. In this study, data privacy refers to the claim of individuals to determine when, how, and to what extent information about them is communicated to others [see 3]. The research questions were as follows: 1) is there a difference in privacy concerns throughout the phases of the customer journey, and 2) how do different service industries differ in terms of privacy concerns? We also discuss about related data analytics theme. This paper consists of four sections. After this introduction, customer privacy concerns in the context of the customer journey have been discussed. Then, the methodology and survey sample have been defined. In the last two parts of the study, conclusions and implications have been discussed.

\section{Data Privacy Throughout the Customer Journey}

Digital service environments and digital tools have become widespread in the service industry in recent years. Although these practices have allowed the target group to participate in a branded e-marketplace, consumer advocates have expressed growing concern about the invasion of privacy caused by e-marketers' information collection practices [8]. Customer interaction, which may be one of the most important elements in service delivery [see 4], looks quite different in digital servicescapes than in traditional personal interactions between services clerks and customers. Moreover, the development of marketing and service practices using consumer data and analytics has advanced rapidly in recent years, which has raised data privacy concerns among consumers.

\subsection{Privacy Concerns}

Previous research $[9,10,11]$ has shown that privacy concerns affect online customer behavior during the use of digital services. Customers may become concerned if they 
feel that their privacy has been invaded or threatened in some way [2]. News items about the vulnerability of digital services and stolen private data promote privacy concerns among customers. The vulnerability of digital services also creates potential business risks for companies [12]. Privacy concerns are also directly connected to customers' purchase behavior, as online stores require customers to provide personal information while shopping online [2,4]. Customers are mindful of privacy concerns while shopping online. However, this may create a competitive advantage for companies who are good at creating online trust between customers and service providers [13]. Previous research has shown that customers felt fewer privacy concerns when they interacted with trusted retailers $[9,10]$. Additionally, good control over customers' shared personal information and visible data collection processes have been shown to improve trust $[14,15]$.

Many factors, including information type, situational factors, the features of service providers, and the individual characteristics of customers have been shown to affect customer's privacy concerns $[10,11]$. However, there are differences between individual customers [16], as each observes the potential risks of online shopping for products and services differently [17]. Gender differences and the health of individuals may also influence privacy concerns [11].

\subsection{Customer Journey}

A customer journey can be defined as 'a description of customer experience where different touchpoints characterize customers interaction with a brand, product, or service of interest' [18]. Følstad and Kvale [19] highlight the processual and experiential aspects of services as seen from the customer's viewpoint. It is described as the repeated interactions between a service provider and the customer within a customer journey. Customers interact with service providers via different digital touchpoints throughout their customer journey [20]. In the omni-channel environment, customer interactions often follow a non-linear structure. Additionally, the critical interaction is with the brand, not with the channel [21]. This scenario is typical in digital platform interactions in general and in the service industry. Customers may use multiple devices in different phases of their customer journey. During the early stages of a customer journey, when contacting a potential customer, search engines, Search Engine Marketing (SEO), Search Engine Marketing (SEM), and display ads play a critical role. For example, search engine results pages present a convenient way for consumers to gather information about service brands [22]. Behavioral targeting connects consumers with brands based on data relating to their past online behaviors. These data could comprise web pages they have visited, the time they spent on each page, and the things they put in their shopping baskets or purchased online [23]. All these actions, which are based on the use of customer data, take place in conversions during a customer journey.

\subsection{Service Industries}

Service industries differ across many attributes. Early service industry categorization 
and conceptualization focused on distinguishing the characteristics of service delivery from the sale of physical products [see 24, 25]. Service industry classification has focused on service delivery or encounter-based activities or solutions, including social interaction and perceived risk [26] and service script-based classifications [27]. It has also involved examining the level of emotional attachment or investment a customer has in the customer experience process, for example, a customer is likely to have a lower level of emotional attachment to purchasing fast food compared to having medical treatment [28]. Cheng, Anderson, Zhu, and Choi [22] have enriched the existing literature on service categorization with their explanation of the complex online service environment. In this study, we have analyzed four different industires; Municipal health stations, Private health stations, Insurance companies, Hobby clubs and Grocery stores. The last two industries represent a low level of perceived risk and purchase effort where consumers are thought to have little involvement, while both health station alternatives represent high involvement service consumption situation. In this classification, we followed Stell \& Donoho [29] line of thinking. In general, customer involvement varies from passive participation of customer, such as simple physical presence, to a very high degree of user integration as a part of the service process [30].

In general, categorization and classification models and concepts help management understand and learn about service operations in different industries [31]. While service industry characteristics modify service encounters and operations in general, it is likely that customers in different service sectors have different levels of concern related to their data privacy when interacting with a company.

\section{Methods}

Data were collected from undergraduate students in Finland, who represented customers of healthcare companies. Student samples are often used in academic research. Yavas [32] states that students are appropriate surrogates in studies where e.g. attitude-behavior relationships or orders of attitudes are researched. University students also represent young digital customers in the omni-channel environments. There were 309 responses, of which 306 were valid and were used in this research. Descriptive statistics revealed that the sample was female-dominant; 67\% $(n=205)$ of respondents were female, and 33\% $(\mathrm{n}=101)$ were male.

Participants were sent an email that included a web-link to the questionnaire. All participants who answered the questionnaire were invited to participate in a lottery that gave them the chance to win minor gifts. We used the questionnaire to measure privacy concerns using four items adopted from Martin et al. [3]. Tradeoff value 
questionnaire items were adopted from Martin et al. [3] and information sensitive items from [33]. In the questionnaire, respondents were asked to rate value using a 5- point Likert scale ranging from totally agree (5) to totally disagree (1). Results were analyzed using Statistical Package for the Social Sciences (SPSS) version 25.0 .

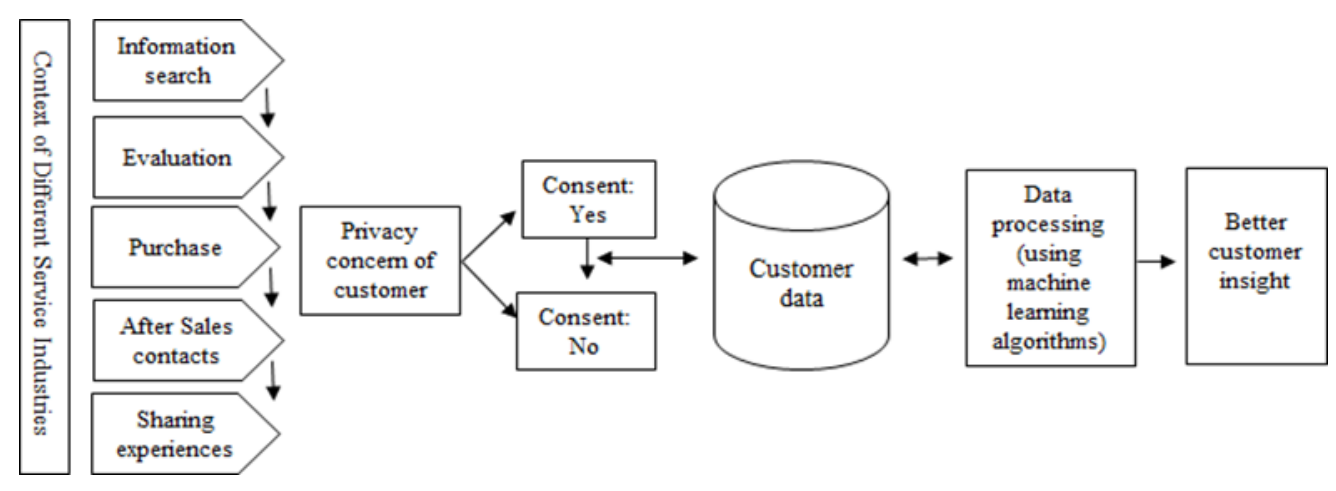

Figure 1. The relationship of customer journey and industry segments to privacy concern.

In Figure 1, a conceptual model of the study has been shown. This study examines how privacy concern vary throughout different phases of the customer journey and in different service industries. The prior research $[9,10,11]$ reveals that privacy concerns affect online customer behaviors. Additionally, information type, situational factors, the features of service providers have been shown to affect customer's privacy concerns $[10,11]$. The individual characteristics of customers also affect to privacy concerns indicating that there are differences between individuals [16]. Furthermore, differences between the phases of customer journey and service industries may be related to information sensitivity, as context and situation affect the behavior of customers. From an interactional psychology perspective, situational factors influence customer behavior and vice versa [34]. Thus, a customer may more easily give their consent to use his or her personal data during different phases of the customer journey and in the context of different service industries. This has significant implications for the digitalization projects of companies and for collaborations with customers in different business ecosystems.

\section{Results}

\section{Data privacy throughout the customer journey}

We analyzed respondents' willingness to share information at different phases of the customer journey. The journey process consisted of information search, alternative evaluation, purchase, after sales contact, and the sharing of information, such as customer experiences and reviews. The model was adopted from Solomon et al.'s[35] customer journey process model. 
Table 1. Respondents' willingness to share their data at different phases of the customer journey.

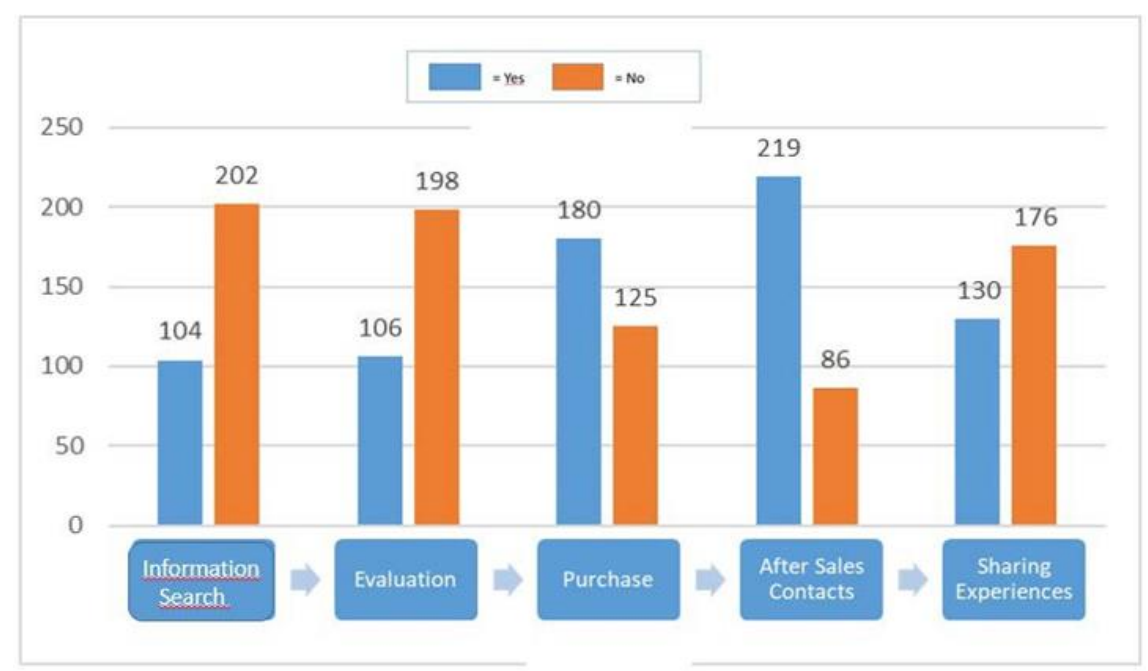

Findings indicated that respondents were more willing to share their data when they were "in buying mode" and actually in the process of buying a product or service. On the other hand, respondents had data privacy concerns at the beginning of their customer journeys. These results challenged current marketing practices, such as re- targeting, which is typically done in a digital environment. We further analyzed the sample according to gender, and there were some indications that female respondents were more willing to interact with the company during the after-purchase phase, but differences were not statistically significant.

\section{Data privacy within different service industries}

We asked respondents how willing they would be to disclose personal information in five different service industry cases.

Table 2. Respondents' willingness to disclose personal information in different service industries $(n=306)$

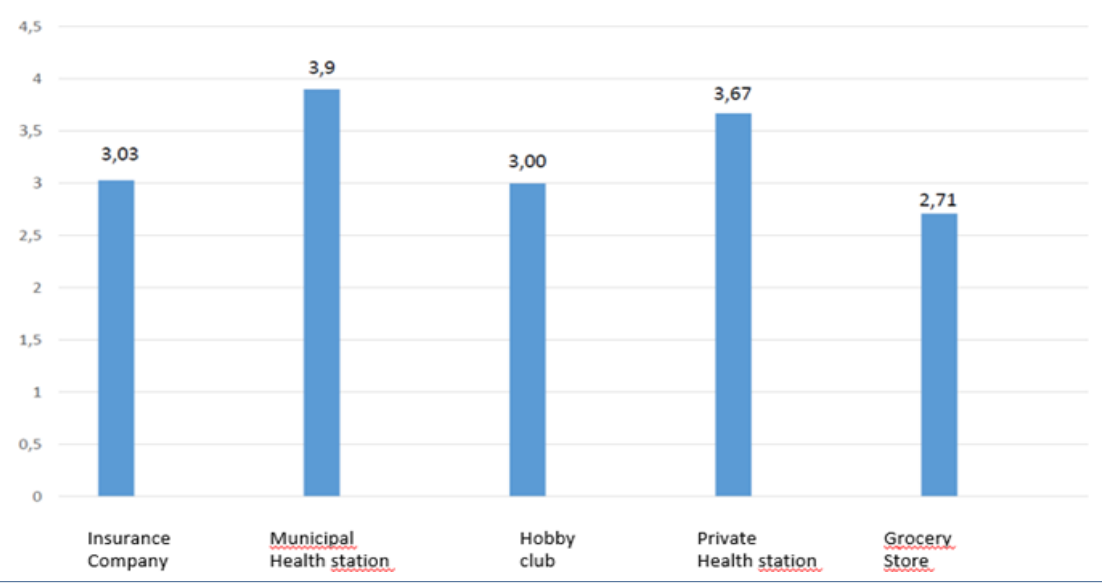

"I do not feel comfortable with the type of information that (service x) requests from me" (totally agree $=1, \ldots$, totally disagree $=5$ ) 
Both private and municipal health stations were examples of services that respondents access with high levels of emotional attachment and cognitive processing, while a grocery store was a service environment in which the role of service encounters was smaller.

Findings indicated that respondents were more willing to disclose their personal data in service settings where they were more involved. Here, involvement referred to consumers' motivation to process product related information at a given point in time [see 35]. The definition also consisted of a person's perceptions of the relevance of an object. We assumed that municipal and private health stations represented service situations where more cognitive processing is likely to take place during a customer journey; hence, the relevance of these settings was higher than in other examples.

We tested our sample with a t-test to explore gender differences in data privacy concerns in different industries.In all industries, female respondents were more willing to share their private information with a company than male respondents. The t-test for equality of means indicated that this difference was statistically significant in insurance company services $(\mathrm{p}=0.02)$ and private healthcare stations $(\mathrm{p}=0.04)$.

\section{Discussion}

The first research question in this study concerned differences in privacy concerns related to the phases of the customer journey. Findings revealed that respondents (72\%) were most willing to share personal data with service providers after their purchase. Of the total sample, 59\% were willing to share their personal data while completing their purchase. Respondents were least willing to share their personal data during the information search (34\%) and evaluation (35\%) phases. Respondents were more willing to share personal data when they were already customers of service providers or when they were purchasing products and services. In these cases, they would have built a relationship with service providers. Respondents had privacy concerns at the beginning of their customer journey, when they would not have developed a formal relationship with service providers.

The second research question concerned differences in privacy concerns across service industries. Results suggested that healthcare information was more sensitive than information concerning purchases from grocery stores, hobby organizations, or insurance companies. Information sensitivity varied across service sectors. Different value chains and business networks deal with different types of information, which may affect the same customer differently. Moreover, our findings indicated that female customers were more willing to interact with companies than male customers.

There is little previous research on privacy concerns throughout the customer journey and in different service industries. This study filled this research gap by exploring personal data disclosure throughout the customer journey and in different service industries. Respondents seemed to focus constantly on information sensitivity and the value that they would receive if they provided personal information. We concluded that at the heart of most privacy concerns is a trade-off between the costs and benefits of the disclosure of personal information. This aligned with prior research suggesting that customers evaluate the pros and cons of a behavior before acting (see, for example, Lanier \& Saini [36].

The current study has contributed to data privacy and service marketing practices in different service industries. Our study supported the personalization-privacy paradox [37], which suggests that personalization can both enhance and diminish customer engagement with the firm. That is, targeted offerings generated by customer data analysis may enhance the customer experience, but they may also raise privacy concerns among customers. The critical issue here appears to be the phase of customer journey. Our findings indicated that the best times for businesses to use customized communication is close 
to when the consumer actually makes a purchase and right after the purchase. This raises concerns over cookie remarketing activities that are typically conducted according to potential customers' browsing behavior. If personalized messages and actions trigger customers' privacy concerns about how the firm is using their personal information, then these may lead to decreased engagement [37 p. 98]. Privacy concerns among customers may increase skepticism toward and avoidance of advertising and can prompt negative actions. All these reactions may reduce overall marketing effectiveness [37 p.99] and harm customer experience. In general, customer experience may be good (enjoyable) or bad (unenjoyable), leading to positive or negative customer response with regard to value, image, quality, patronage, loyalty, satisfaction, recommendations, and purchase intentions [38, p. 655.].

Today's companies operate in collaborative networks that utilize computer networks [39]. Collaborative networks are also becoming data-rich environments [39, 40] and it raises issues such as the privacy concern of customers. Service ecosystems based on collaborative networks include new platform ecosystems who compete in service offering without ownership to a subject [see 41]. They collect and manage data to operate their business ecosystem and several companies participate value creation in different phases of value chains Thus, data sources that are needed to serve and build customer relationships and operative processes are located in collaborative networks of customers, partners, and service providers. From the customer's viewpoint, privacy issues are related to all phases of a customer journey, as each phase is often served and operated by different service providers. For example, search history and marketing relate to marketers, such as Google and advertisement agents, while purchase and payment data are collected by platform owners and payment operators, and service providers deal with usage and customer satisfaction data. Hence, throughout their customer journey, customers interact with many service providers, providing or withholding consent for each to collect their personal data. Data privacy is not a single point event but is a key question in the operations of collaborative networks.

The findings provide new knowledge for marketers about the respondents' information sensitivity concerning different industry segments and privacy concern relating to the phases of customer journey. Privacy concern in different phases of the customer journey often reflects to the different roles of service providers in the value chain of service ecosystems. Marketers should pay attention to these differences in planning data collection and motivating customers to provide consent for the use of their private data in managing omni-channel operations. From the perspective of collaborative networks literature, the findings contribute to the processes of collaborative networks [42], especially to the management and governance of omni-channel service ecosystems.

\section{Conclusions}

This study showed that companies and business networks should consider privacy concerns when planning and designing new digital services. Privacy concerns are closely related to data analytics, which are crucial in digital service delivery. Findings suggested that businesses should focus customer engagement actions close to the actual buying phase and that information sensitivity across different service sectors varied. During the early stages of the customer journey, companies should focus on offering and brand development and possibly SEO activities, which may draw a customer's attention without provoking data privacy concerns. Additionally, companies should give special attention to the visibility of data usage at the beginning of a buying journey.

The basic limitation of this study is its quite small target group consisting of student sample. It limits the generalizability of the results, and this study increases only understanding about the factors that affect the respondents' online behavior. Finally, this study suggested that respecting customers and their data privacy is an investment in relationship building. The results of this study have suggested that researchers should explore privacy concern empirically, especially in the context of value chains and networks, as customers 
deal with several actors throughout their journey. Additionally, the different types of information in different customer journeys merit further research.

Acknowledgments. The authors would like to thank the Big Data-Big Business (BIG) Project, all parties behind the project, and Business Finland (the Finnish innovation funding, trade, investment, and travel promotion organization) for their support of this study.

\section{References}

1. Alamäki, Ari, Rantala, T., Valkokari, K., Palomäki, K.: Business Roles in Creating Value from Data in Collaborative Networks. In: Collaborative Networks of Cognitive Systems. PRO-VE 2018. IFIP Advances in Information and Communication Technology, vol 534, pp. 612-622. Springer, Cham (2018)

2. Ackerman, M. S., Cranor, L. F., Reagle, J.: Privacy in e-commerce: Examining user scenarios and privacy preferences. In Proceedings of the 1st ACM conference on electronic commerce, ACM, pp. 1--8 (1999)

3. Martin, K. D., Murphy, P. E.: The role of data privacy in marketing. Journal of the Academy of Marketing Science, 45(2), 135--155 (2017)

4. Walter, U., Edvardsson, B., ̊̊. Öström.: Drivers of customers' service experiences: A study in the restaurant industry. Managing Service Quality, 20(3), 236--258 (2010)

5. Malhotra, N. K., Kim, S. S., Agarwal, J.: Internet users' information privacy concerns (IUIPC): The construct, the scale, and a causal model. Information Systems Research, 15(4), 336--355 (2004)

6. Kolah, A., Foss, B.: Unlocking the power of data under the new EU general data protection regulation. Journal of Direct, Data and Digital Marketing Practice, 16(4), 270-274 (2015).

7. Mitchell, A.: GDPR: Evolutionary or revolutionary? Journal of Direct, Data and Digital Marketing Practice, 17(4), 217--221 (2016)

8. Youn, S.: Determinants of online privacy concern and its influence on privacy protection behaviors among young adolescents. The Journal of Consumer Affairs, 43(3), 389--418 (2009)

9. Chellappa, R. K., \& Sin, R. G.: Personalization versus privacy: An empirical examination of the online consumer's dilemma. Information Technology and Management, 6(2-3), 181--202 (2005)

10. Bleier, A., Eisenbeiss, M.: The importance of trust for personalized online advertising. Journal of Retailing, 91(3), 390--409 (2015)

11. Wilkowska, W., Ziefle, M.: Privacy and data security in E-health: Requirements from the user's perspective. Health Informatics Journal, 18(3), 191--201 (2012)

12. Martin, K. D., Borah, A., Palmatier, R. W.: Data privacy: Effects on customer and firm performance. Journal of Marketing, 81(1), 36--58 (2017)

13. Bart, Y., Shankar, V., Sultan, F., Urban, G. L.: Are the drivers and role of online trust the same for all web sites and consumers? A large-scale exploratory empirical study. Journal of marketing, 69(4), 133--152 (2005)

14. Culnan, M. J., Armstrong, P. K. Information privacy concerns, procedural fairness, and impersonal trust: An empirical investigation. Organization Science, 10(1), 104--115 (1999)

15. Phelps, J., Nowak, G., Ferrell, E.: Privacy concerns and consumer willingness to provide personal information. Journal of Public Policy \& Marketing, 19(1), 27-- 41 (2000)

16. Sjöberg, L.: Factors in risk perception. Risk Analysis: An International Journal, 20(1), 1-12 (2000)

17. Nordin, F., Kowalkowski, C.: Solutions offerings: A critical review and reconceptualisation. Journal of Service Management, 21(4), 441--459 (2010)

18. Wolny, J., Charoensuksai, N.: Mapping customer journeys in multichannel decision-making. Journal of Direct, Data and Digital Marketing Practice, 15(4), 317--326 (2014)

19. Følstad, A., Kvale, K.: Customer journeys: A systematic literature review. Journal of Service Theory and Practice, 28(2), 196--227 (2018)

20. Hallikainen, H., Alamäki, A., Laukkanen, T.: Individual preferences of digital touchpoints: A latent class analysis. Journal of Retailing and Consumer Services. (advanced online publication) (2018) 
21. Elizabeth, M. P., Peltier, J. W., Barger, V. A.: Omni-channel marketing, integrated marketing communications, and consumer engagement. Journal of Research in Interactive Marketing, 11(2) (2017)

22. Cheng, M., Anderson, C. K., Zhu, Z., Choi, S. C.: Service online search ads: From a consumer journey view. The Journal of Services Marketing, 32(2), 126--141 (2018)

23. Yu, S., Hudders, L., Cauberghe, V.: Targeting the luxury consumer. Journal of Fashion Marketing and Management, 21(2), 187--205 (2017)

24. Brown, S. W., Fisk, R. P., Bitner, M. J.: The development and emergence of services marketing thought. International Journal of Service Industry Management, 5(1) (1994)

25. Grönroos, C.: Service Management and Marketing: A Customer Relationship Management Approach. Wiley \& Sons (2001)

26. Johnston R. \& Clark G.: Service Operations Management. Pearson Education (2001)

27. Shoemaker S.: Scripts: Precursor of consumer expectations. Cornell Hotel and Restaurant Administration Quarterly, 3(1) 42--53 (1996)

28. Bolton, R. N., Gustafsson, A., McColl-Kennedy, J. R., Sirianni, N. J., Tse, D. K.: Small details that make big differences: A radical approach to consumption experience as a firm's differentiating strategy. Journal of Service Management, 25(2), 253--274 (2014)

29. Stell, R., Donoho, C. L.: Classifying services from a consumer perspective. The Journal of Services Marketing, 10(6), 33--44 (1996)

30. Dadfar, H., Brege, S., Sedigheh Sarah, E. S.: Customer involvement in service production, delivery and quality: The challenges and opportunities. International Journal of Quality and Service Sciences, 5(1), 46--65 (2013)

31. Payane, A.: The Essence of Services Marketing. Prentice- Hall, New York (1993)

32. Yavas, U.: Research note: students as subjects in advertising and marketing research. International Marketing Review, 11(4), 35--43 (1994)

33. Dinev, T., Xu, H., Smith, J. H., Hart, P.: Information privacy and correlates: An empirical attempt to bridge and distinguish privacy-related concepts. European Journal of Information Systems, 22(3), 295--316 (2013)

34. Terborg, J. R.: Interactional psychology and research on human behavior in organizations. Academy of Management Review, 6(4), 569--576 (1981)

35. Solomon R. M., Bamossy, G. S., Askegaard, R., Hogg, M. K.: Consumer Behaviour - A European Perspective. Prentice-Hall, New Jersey (2016)

36. Lanier, C. D., Saini, A. Understanding consumer privacy: A review and future directions. Academy of Marketing Science Review 12(2), 1--48 (2008)

37. Aguirre, E., Roggeveen, A. L., Grewal, D., Wetzels, M.: The personalization-privacy paradox: Implications for new media. The Journal of Consumer Marketing, 33(2), 98--110 (2016)

38. Jain, R., Aagja, J., Bagdare, S.: Customer experience - a review and research agenda. Journal of Service Theory and Practice, 27(3), 642--662 (2017)

39. Camarinha-Matos L.M., Fornasiero R., Afsarmanesh H.: Collaborative Networks as a Core Enabler of Industry 4.0. In: Collaboration in a Data-Rich World. PRO-VE 2017. IFIP Advances in Information and Communication Technology, vol 506, pp 3--17. Springer (2017)

40. Bruno, G., Antonelli, D., Villa, A.; A reference ontology to support product lifecycle management. Procedia CIRP, 33, 41-46 (2015)

41. Appio, F. P., Martini, A., Massa, S., Testa, S.: Collaborative network of firms: antecedents and state-of-the-art properties. International Journal of Production Research, 55(7), 2121--2134 (2017)

42. Barile, S., Lusch, R., Reynoso, J., Saviano, M., Spohrer, J.: Systems, networks, and ecosystems in service research. Journal of Service Management, 27(4), 652--674 (2016) 